\title{
Creating Stimulating Learning And Thinking Using New Models Of Activity-Based Learning And Metacognitive-Based Activities
}

\author{
Katherine Pang, University of Texas at Tyler, USA
}

\begin{abstract}
The purpose of this paper is to present a novel way to stimulate learning, creativity, and thinking based on a new understanding of activity-based learning $(A B L)$ and two methods for developing metacognitive-based activities for the classroom. ABL, in this model, is based on the premise that teachers are distillers and facilitators of information who scaffold learning based on the foundations that learners build outside of the classroom from the deployment self-facilitated metacognitive aptitudes. In the ABL model presented in this paper, teachers develop learner selfregulation and self-facilitation by stating expectations that promote learner responsibility while integrating instructional strategies to foster activity-based learning through a new paradigm of thinking based on awareness, evaluation and implementation (AEI), and a new constructiondeconstruction connectionist (CDC) model of learning.
\end{abstract}

Keywords: Stimulating Learning; Thinking Strategies; Models of Learning; Assessments; Metacognitive Instruction; Metacognitive Development; Metacognitive Activities; Activity-based Learning

\section{INTRODUCTION}

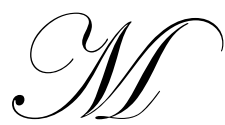

any students face the challenges of adapting to instructional styles and expectations that differ from previous academic experiences. For many students, college challenges their level of motivation and requires significant adjustments to academic aptitude, but standard curricula usually provides little or no help in identifying and overcoming the barriers to learning (Newell, Dahm, Harvey, \& Newell, 2004) or the development of metacognitive skills. Student awareness and understanding of their learning skills, performance, preferences and barriers is one type of metacognitive understanding which requires that a student be both self-aware and self-directed; yet these issues are often overlooked by faculty in the development of curricula and instruction in the classroom. Based on the need to consider novel ways to stimulate learning, the purpose of this paper is to share a new understanding of activity-based learning (ABL) and two methods for developing metacognitive-based activities for the classroom. ABL, in this model, is based on the premise that teachers are distillers and facilitators of information who scaffold learning based on the foundations that learners build outside of the classroom from the deployment self-facilitated metacognitive aptitudes. In the ABL model presented in this paper, teachers develop learner self-regulation and self-facilitation by stating expectations that promote learner responsibility while integrating instructional strategies to foster activity-based learning.

\section{METACOGNITIVE-BASED COGNITIVE DEVELOPMENT}

According to cognitive-developmental theories, cognitive development includes both intellectual maturity and metacognitive superiority. Historically, metacognition has been described as "thinking about your own thinking" or "reflections on cognition" (Schoenfeld, 1987). Flavell (1979) defined metacognition as "knowledge about cognition about cognitive phenomena." Hofer and Pintrich (1997) believed that intellectual development was reflected in one's metacognitive beliefs about knowledge and knowing. Pintrich (2000) makes the point "if students 
do not realize they do not know some aspect of factual, conceptual, or procedural knowledge, it is unlikely they will make any effort to acquire or construct new knowledge" (p. 222). Research has shown that students have an "illusion of knowing" (Hofer, Yu, \& Pintrich, 1998; Ormrod, 1999; Pintrich, McKeachie, \& Lin, 1987) which is usually the result of a failure to properly monitor and evaluate one's cognition. Intellectual maturity is also important for reasoning (Kuhn, 1991), thinking (King \& Kitchener, 1994), and understanding (Basseches, 1984). Kegan (1994) demonstrated that metacognition is essential for reflective thinking and evaluative decision-making. Empirical studies have shown (i.e., Minnaert \& Janssen, 1992) that numerous cognitive variables and psychological constructs influence a student's success in higher education. In such it has been shown that intellectual maturity and metacognitive superiority are indicators of cognitive development in college students.

Since McKeachie (1974) there has been continued discussion on how specific teaching strategies impact a learner and the learner's learning experience. Questions regarding type of instruction, such as lecture, in class exercises, collaborative assignments, and the appropriate combination of instruction types have been the topic of significant research over the last thirty years. While many scholars have examined various variables and their relationship to the learner's experience there remain significant questions on what has perceived value to the learner. Since the mid 1990s traditional passive, behavioral approaches to teaching and learning have succumbed to more constructivist based views that recognize learners as active participants in their learning experience (Salas \& Cannon-Bowers, 2001). The active, constructivist theory is based on the view that learners are active processors of content, in control of their own learning (Winne \& Hadwin, 1998) and are active agents assuming responsibility and management for in their own learning process. Research has demonstrated that active learning promotes the development of self-regulation and self-facilitation skills (Ivancic \& Hesketh, 2000) which are the main components of metacognition (Flavell, 1979; Brown, 1987). For example, Stewart, Cooper, and Moulding (2007) found that students with developed metacognitive skills achieved greater academic success than students will less developed skills. Therefore, it would appear that a pedagogy derived from instructional strategies that facilitate metacognitive ability derived from active learning would not only improve learner performance but enhance the overall learner experience. Further, research has shown that a learner's knowledge about his or her own thinking, metacognition, impacts learning outcomes, and manifests in learners' efforts towards learning (Flavell 1992; Hartman, 2001).

Cannon-Bowers, Rhodenizer, Salas, and Bowers (1998) noted that "metacognition emphasizes selfmonitoring of one's cognitive functions, which assists learners in becoming active in their education instead of being passive recipients of instruction" (p. 296). Since the primary components of metacognition require self-regulation, planning, and monitoring in order to develop these skills learners need a learning environment that facilitates selfdirected and active learning (Sweller, Mawer, \& Ward, 1983; Novick \& Holyoak, 1991). This type of learning is an inductive process, where learning is developed through exploration and experimentation that stimulates the development of metacognitive ability (Ford \& Kraiger, 1995) as contrasted with a more deductive method where learner exploration is constrained by a passive pedagogy (Keith \& Frese, 2005). Further, active learning requires skills of adaptive transfer where learners can create new scenarios and solutions to demonstrate understanding and then evaluate effectiveness (Ivancic \& Hesketh, 2000) based on a construction-deconstruction connectionist process model. As a result the pedagogical choice should be based in a constructivist ideology that integrates instructional strategies in the learning experience that cultivate active learning.

\section{ASSESSING METACOGNITIVE ABILITY: THE ME-ATTM}

Today, there is little dispute among scholars that there are core components of cognitive and metacognitive processes that extend across domains in defining academic success. Recent research demonstrates that if a student is more metacognitively aware he or she will be more successful in cognitive endeavors (Garner \& Alexander, 1989). According to Desoete, Roeyers, and De Clercq (2003) metacognitive development and movement from novice to expert is more likely when there is explicit metacognitive instruction. Based on these findings and the concept that there is an overarching strategy implicit in the development of metacognitive knowledge (Pintrich, 2000), particularly in how students plan, monitor, and regulate cognition, Pang (2008) developed a model of metacognitive expertise that was based on four metacognitive domains; metacognition of self, metacognition of learning environment, metacognition of professor, and metacognition of classmates (Metacognitive Domains); and 10 component factors; (a) motivation, (b) self-confidence, (c) self-regulation, (d) cognitive artifacts, (e) affect, (f) environmental scanning, (g) personal epistemology, (h) prompting, (i) self-efficacy, and (j) inner speech 
(Component Factors). These Metacognitive Domains and Component Factors were then used to develop a 50 question, 7-point Likert scale to assess metacognitive expertise, known as the Metacognitive expertise assessment tool (the ME-AT ${ }^{\mathrm{TM}}$ ). A major reason for the development of the ME-AT was to fill a void for a valid and reliable instrument that measures metacognitive expertise in high achievers based on a collection of 10 Component Factors operating within the context of four Metacognitive Domains that could be used as a predictive instrument for academic achievement and used by faculty to design curricula to stimulate meaningful learning (see Figure 1).

Figure 1: Metacognitive Component Factor and Domain Cycle

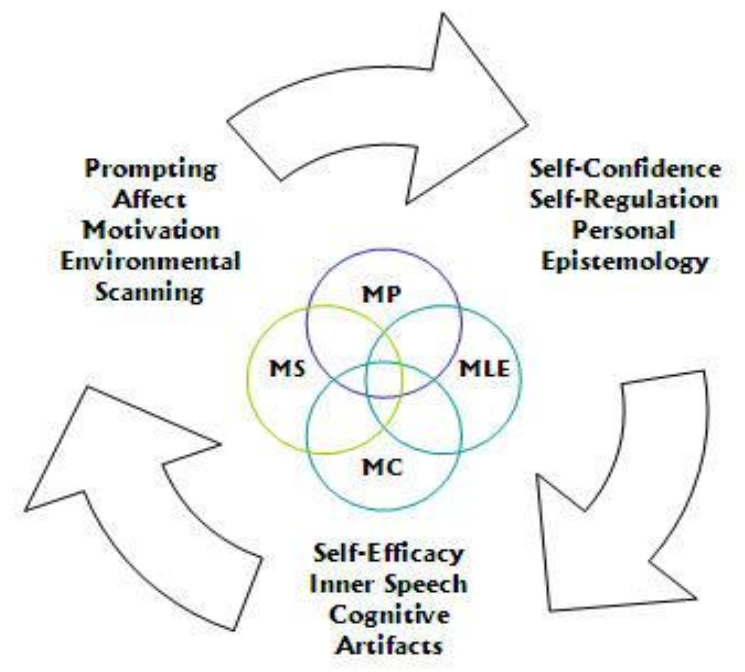

In research conducted by Pang (2008) the psychometric properties of the ME-ATTM were validated in two studies using multiple regression and correlation analysis that established the ME-AT ${ }^{\mathrm{TM}}$ as a predictive measure of academic achievement as measured by grade point average. In a third study, the ME-AT ${ }^{\mathrm{TM}}$ and Metacognitive Awareness Inventory (MAI, Schraw \& Dennison, 1994) was administered and the findings revealed that three of the Metacognitive Domains and all 10 of the Component Factor predictors from the model of metacognitive expertise as represented in the ME-AT ${ }^{\mathrm{TM}}$ significantly discriminated low achievers from high achievers, whereas the MAI did not significantly discriminate low achievers from high achievers. Based on these findings, it became apparent that metacognition should not be promoted to the detriment of subject matter development (Georghiades, 2004); but rather should be connected and intertwined in metacognitive-driven activity-based instruction. Metacognitive learners must understand not only their individual strengths and weaknesses in learning but learn from metacognitive-based strategies and activities that are derived from the Component Factors (Pang, 2008). As Ellis (2001) posits, in order for a student to successfully engage in metacognitive strategies, the student must engage what Pang has termed the Metacognitive Domains, and extract from the classroom environment as well as the professor. As Ormord (1999), noted the more successful students will monitor themselves, ask questions, and engage all aspects of learning, which include according to my model - the learning environment, the professor, and other classmates.

\section{DEVELOPING AN ACTIVE, CONSTRUCTIVIST PEDAGOGY}

According to Huitt (2003), the emphasis of the constructivist approach is that "an individual learner must actively build knowledge and skills (e.g., Bruner, 1990) and that information exists within these built constructs rather than in the external environment" (p. 386). In active learning the learner must assume responsibility for the learning experience. The learner has control and makes choices as to engagement and outcome; it is a learnercentered environment. Bonwell and Elison (1991) define active learning as "anything that involves students in doing things and thinking about the things they are doing" (p. 2). Active learning, therefore, requires the metacognitive components of self-regulation, monitoring and reflection. In contrast, traditional passive learning environments, 
such as lectures where the learning is instructor-centered, the learning is not inquiry-based, participatory, or collaborative requiring the learner only to deposit information for later use. Researchers (i.e., Dean, 2006; Douglas, Burton \& Reese-Durham, 2008) have found that this type of passive information-dissemination direct instruction, when compared to more robust methods of instruction, have fallen significantly short in developing strong cognitive abilities and academic skills. Active learning, on the other hand, emphasis an inductive methodology where there is learner experimentation and knowledge construction (Wells, 1985).

Contemporary views of learning suggest that the learner's knowledge construction process is based on experiences and beliefs; a derived epistemology which scaffolds based on the continual interaction between the learner and the experience (Bransford, Brown, \& Cocking, 2000). In this context active learning requires not only metacognitive development but an understanding of one's self in the learning process. In designing learning based on an active, constructivist approach, professors elevate levels of understanding, generate self-confidence and motivation, among other psychological constructs (Pang, 2008), and promote deeper learning. For example, Reeves and Francis (2002) in a study emphasizing problem-based learning found that pharmacy students were more inquisitive in the learning process which impacted retention of the content and its application to new scenarios. Vaughn, Gonzalez del Rey and Baker (2001) developed a novel instructional method, they named "microburst learning" that combined role-plays, experiential activities, group discussions, and simulations which were presented as "short bursts" and found correlations to more effective learning which included increased attention and motivation. In research on the development of metacognitive expertise, based on a new model, Pang found that personal epistemology was one of ten components comprising metacognitive expertise which is correlated to academic success.

Personal epistemology research has examined learners' beliefs about the nature of knowing and knowledge (Hofer, 2004; Schraw \&Sinatra, 2004) and has demonstrated that learners with more complex and refined beliefs performed better in academic achievement (Schommer, 1993) and conceptual change learning (Mason, 2003). From an instructional strategy perspective, Giesbrecht (2000) advocated that "instructional strategies that provide an epistemological pluralism and accept the validity of multiples ways of knowing and thinking are recommended" (p. 2). A learner's personal epistemology provides insights on his or her views about the nature of his or her knowledge and allows learners to make personal connections. These epistemological beliefs have been found to not only be related to ways of learning but also to how learners approach processing learning tasks (Hofer \& Pintrich, 1997). In additional research, Hofer (2004) and Tsai (2004a) asserted that a learner's epistemology guides cognitive and metacognitive activities in various learning environments. Research into beliefs has revealed that certain learners view learning as understanding via knowledge construction, representing a constructivist perspective, whereas other learners view learning as memorization and recollection or knowledge reproduction, representing a more passivist learner orientation (Bereiter \& Scardamalia, 1989; Chan \& Sachs, 2001). Learners who view learning as a knowledge reproduction task tend not to personalize or internalize the learning experience while learners who are constructivist and oriented towards knowledge construction tend to be "inherently progressive" (Bereiter \& Scardamalia, 1993, p. 165), engaged internally, and active in searching for deeper understanding. The connection between an active, constructivist-oriented instructional strategy that engages metacognitive skills activities with various components that are essential for learner success, such as motivation and personal epistemology is more meaningful for learner development. Studies continue to reveal that learners with well-developed constructivistoriented, epistemological beliefs demonstrate more advanced and deeper higher-level thinking (Fink, 2003) and decision-making. (Tu, Shih, \& Tsai, 2008). It is, therefore, apparent that transforming instructional pedagogy to foster active learning is necessary for more effective and meaningful learning.

\section{CHANGING PARADIGMS}

Transformation, however, requires change and change often encounters resistance and is perceived as a difficult process. If professors are willing to change paradigms and modify classroom practices as well as personal epistemologies (Havita, 2000) change can be effectuated from more traditional, passive presentational practices to more metacognitive-based multicontextual practices as required for active learning. For transformation, a professor must commit to an explicit pedagogy emphasizing inquiry, reasoning, and exploration. Implicit in this practice are principles of engagement, motivation, and the development of metacognitive abilities that equip learners to process information and that create an awareness of helpfulness that is valued by the student. Building on the research of 
Wells (1985), who advocated that knowledge must be actively constructed, to foster active learning instructional strategies must promote an activity-based learning pedagogy through the promotion of meaning-making and learning extracted from active knowledge construction by learner-driven, regulated, and managed classroom activities. In order to assist in this change, this paper presents a model that fosters active learning based on an understanding that learners learn better when they are engaged and involved in their learning (Gaffam, 2007). This novel model has been designed to shift the responsibility for learning to the learner in the acquisition and application of domain specific content while building the metacognitive skills necessary for academic success and a meaningful learning experience (Brown \& Campione 1994).

\section{The AEI Model}

In further efforts to integrate metacognitive awareness into instructional design, it is necessary to inquire as to: (a) how professors can move from direct instruction to instruction that drives thinking and develops metacognitive abilities in college students? And (b) how professors can maximize a student's potential by developing self-regulated, active learning that spurs thinking and results in deeper processing? In order to answer these questions, it is necessary to construct a new paradigm based on awareness, evaluation and implementation (AEI). The AEI is a new model in which the framework presents a holistic perspective for developing a disposition towards thinking that moves the student along a novice-to-expert continuum of metacognitive development. The fundamental underpinnings of the AEI model of developing thinking skills stems from the premise that making meaning, for the novice, is limited to interpretations, categorizations, and semantics based on prior and current knowledge; knowledge that is superficial and resting on the surface - knowledge that is received by the student as a passive recipient. This type of meaning-making and knowledge reception is reinforced by the presentational style of teaching found in many large core courses. As a result students fail to develop the disposition to think which flows into higher-level course deficiencies in thinking skills and the development of metacognitive abilities leading to metacognitive expertise.

The AEI model, depicted below, illustrates that thinking drives the development of metacognitive skills that drive the further development of higher order and deeper processing thinking that drives momentum towards metacognitive expertise (see Figure 2). The main components of the model are: assessment, evaluation, and implementation. Assessment includes three sub-elements: identification, investigation, and interpretation. Evaluation consists of analysis and synthesis. Implementation is composed of framing, explaining, regulating, and evaluating.

To illustrate an application of the AEI model students in a criminal law class were asked to complete homework questions based on certain textbook questions. One question was "what's the difference between the mental states of purpose and knowledge? Give an example of each" (Samaha, 2008, p. 133). The students were instructed in class to "think beyond the boundaries of the question" when answering the homework question and were also instructed to provide well-reasoned analysis and develop paragraphs that demonstrated understanding of the relevant materials. Students were reminded that one or two sentences would not be sufficient in answering these types of questions. The homework was due the next class (which was a Monday, since the homework was assigned on a Friday). The students had ample time to complete more in-depth and thinking-derived answers to the homework question. In addition, the class session in which the homework was due (Monday) was devoted to discussing the completed homework question in class so as to deconstruct the thinking process applied to the completion of the homework, reinforce important substantive points, and illustrate more advanced thinking procedures. In class, the professor used the AEI model to guide a class discussion on this homework problem. The professor first asked the entire class, "When you read this question, what did you think you needed to do to successfully answer it?" Some students answered "we needed to define the terms, purpose and knowledge, and then identify differences." The professor pointed out that the answer was a good first step but that it was equally important to think about what the question was asking - to identify the tasks within the question so as to focus on answering what the question was asking in terms of deeper, richer answers. For example, the first step was to identify that the question really had three parts, although only two were explicitly stated in the question. The first part was implicit; logically it was impossible to discuss differences if the first step was not performed so as to identify relevant and material characteristics of the terms. For example, how can a student discuss the difference between an apple and an orange without noting characteristics about shape, color, taste, etc? The second and third steps were explicit in that the second step was to discuss the differences and the third step was to give an example. 
Figure 2: AEI Model

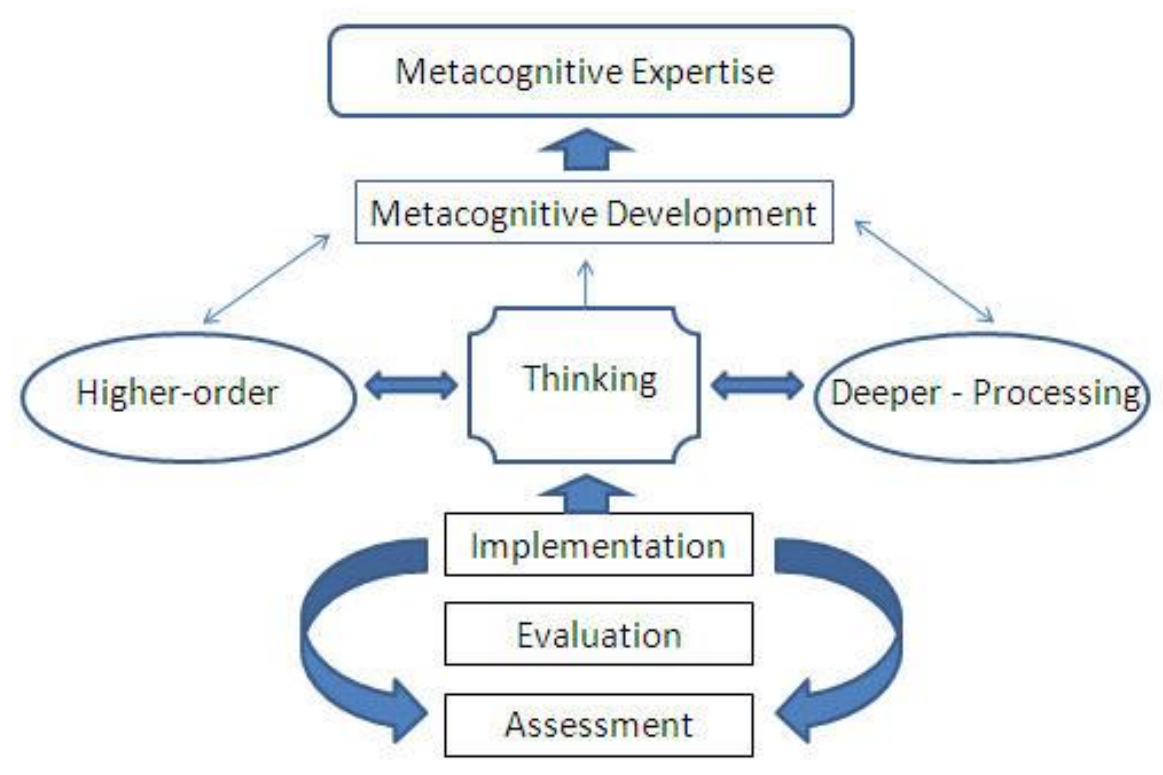

The Construction-Deconstruction Connectionist Model (CDC)

This novel model is based on a collaborative active learning in-class activity, which can be named: "Name that Theory," "Name that Crime," "Name that Principle," etc. The model is built upon the premise that for purposes of classroom learning, learning is not only a cognitive event but is a psycho-dynamic, social process that needs to consider the four metacognitive domains that manifest in an academic environment. These include: (a) the student (metacognition of self); (b) the classroom (metacognition of learning environment); (c) the professor (metacognition of professor); and (d) other students (metacognition of classmates) (Pang, 2008).

In this new construction-deconstruction connectionist model, both the construction and deconstruction processes operate in a connectionist manner. Central to this model is the premise that learning must be chunked and connected. Chunking is a concept that is familiar in literature on the development of expertise and is used to explain the development of mental representations (Egan and Schwartz (1979). For purposes of this model, the main points or principles of the theory, or the main elements of a Statute, are chunked by learners to facilitate learning through association, connections, and representations. This process of chunking and connecting content allows learners to apply the content with greater facility, speed, and ease in the deconstruction and connectionist steps in the model. In essence, for this model it is an efficient way of organizing information for later retrieval; a form of parsing. From an instructional strategy perspective, the learner must be encouraged to develop relevance through connection and demonstrate scaffolding through knowledge construction and deconstruction. The acquisition of knowledge and the development of understanding, what we refer to as learning, is therefore generated through activation of chunked components of content that are represented in the construction and deconstruction process through a progressive scaffolding that is continually upgrading previously established associations of content knowledge. In such, the construction-deconstruction connectionist process model that was developed for purposes of this research has four scaffolding steps

The first step in this model is the process of construction. Simply stated, construction is the development or building of a fact pattern, hypothetical, illustration, or scenario from scratch without guidance, input, or direction from the professor. Construction involves the learner in developing a context that adequately explains or illustrates a concept, theory, or principle from original individual or collaborative thought. In order to successfully engage in construction a learner must understand the component constructs of the concept, theory, or principle in sufficient detail so as to construct a contextual environment for its representation. The second step requires deconstruction. 
Deconstruction requires the extraction and identification of the main or material components or concepts embedded in the fact pattern, hypothetical, illustration, or scenario. Simply stated, deconstruction is the disassembly of the constructed artifacts. In order to demonstrate understanding of the main or material components of the assigned concept, theory, or principle learners in the second step must rightly represent the theory in a heuristic analogous to reverse engineering or deconstruction in architectural-driven learning activities (Ccolajanni, Concialdi, \& Pellitteri, 2001) or component architecture in web-based environments (Stearns, Gargus, Schuetze, \& Lombardi, 2006).

The third step highlights understanding through connection. According to Kintsch (1998), for purposes of illustrating comprehension, there is a mapping process between the new knowledge and preexisting knowledge structures. This mapping is illuminated in the third step of the model which is the concept of connection. In this step the learner connects the assigned concept, theory, or principle to the words or sentences in the fact pattern, hypothetical, illustration, or scenario that are illustrative of the theory demonstrating an ability to perform illustrative connections. The ability to connect chunked components of a theory to illustrative exemplars of the theory develops a type of coherence from which the learner can draw inferences to illustrate understanding in the fourth step. The purpose of the fourth step is to provide an opportunity for the learner and the professor to glean insights on the illustrative connection process through the learner's demonstration of more expert understanding. In providing commentary or explanatory text as annotations to the illustrative connections in the third step, learners reveal their reasoning processes. Inherent in the constructivist, active learning paradigm is the belief that learners who develop active learning skills tend to seek meaning and understanding and are more adept at integrating new knowledge with existing knowledge as demonstrated in the third step (Law, Chan, \& Sachs, 2008). Developing commentary provides further insights into a learner's understanding and research has shown that students who use constructivist, active strategies are more engaged in the learning process (Ainley, 1995).

To illustrate the CDC model learners in a 50-minute class session were assigned to groups of 3-6 students. The groups were assigned a concept, theory, or principle that had previously been discussed in class. Learners in the group were instructed to construct a fact pattern, hypothetical, illustration, or scenario of the assigned concept, theory, or principle and turn it in at the end of class. In the next 50-minute class session, the learners were asked to sit in the same groups from the last class and were asked to write down the name of the concept, theory, or principle when the assignments was read to the entire class. The professor read the assignments aloud to the entire class and the groups had 1 minute to write down the name of the theory. When all of the assignments were read aloud, the professor asked the groups to name that theory. The groups who were correct were asked to place a check on their score card and an " $\mathrm{x}$ " next to their answer, if they were incorrect in their choice. The score cards were then collected by the professor. In the next 50-minute class the assignments were returned to the original groups and they were provided a copy of one other group's assignment and were asked to deconstruct the fact pattern, hypothetical, or illustration by highlighting, circling, underlining or otherwise identifying the main or material components of the assigned concept, theory, or principle and then connecting it to the words or sentences in the fact pattern, hypothetical, or illustration that illustrated the main or material components of the assigned concept, theory, or principle.

\section{SUMMARY}

In conducting research on creating stimulating learning environments and academic performance, it has become evident that there is a culture and, therefore, a learner expectation that often teachers are tellers of information rather than facilitators of learning. The learner has adapted to a passive learning environment where the class experience is where information is imparted through lecture and PowerPoint presentations rather than interpretive and application skills developed through activity-based learning. In passive learning cultures where the traditional model is presentational, what is the motivator for reading the textbook if the professor tells the learner what he or she needs to know in class, via a lecture? Why come to class if a learner can read the textbook and download PowerPoints from the web? If professors perpetuate a passive learning culture, we cannot be surprised by disengaged students and absenteeism? If the remedy is taking attendance or administering accountability quizzes, then we are not changing the culture, only promoting passivity with a behaviorist reward-punishment analgesic. In order to develop sustainable constructivist-active learning designed to motivate, engage, and equip learners, professors must change our instructional methods and adopt instructional design strategies that integrate ABL concepts. 
Developing AEI thinking and CDC activity-based learning requires movement away from presentational lecture, which promotes passive learning, and homework and assessments, which reward only recall and recognition to active learning activities and assessments that develop thinking skills derived from cognitive and metacognitive operations. This requires an emphasis on cooperative learning where the professor demonstrates his/her 'expert' thinking process by deconstruction and construction of homework questions by talking through the AIE phases and teaching steps to promote and challenge learning. In many ways, this is a cultural change process that first starts with the professor shifting paradigms and implementing pedagogical strategies that emphasize shared thinking and reasoning to build on existing knowledge and explore how to develop transfer skills so as to build framing, explaining, regulating, and evaluating in the AEI implementation phase. This methodology must be predicated on a social constructivist, active learning perspective where transformation to a creative, stimulating learning environment is the primary goal.

\section{AUTHOR INFORMATION}

Dr. Pang is a faculty member in the Department of Social Sciences at the University of Texas at Tyler. Dr. Pang has a PhD in educational psychology as well as a Masters in Psychology, a Masters in Educational Technology, an MBA, and two law degrees. Dr. Pang has published numerous empirical studies in various academic journals pertaining to cognition and teaching. Dr. Pang is concentrating significant research efforts on the effects of metacognition on learning and teaching. Dr. Pang is a member of numerous professional associations and is a reviewer for The International Journal of Learning as well as for several education-oriented conferences, such as CELDA. Dr. Pang has over 15 years of experience in the design, development and delivery of educational courses and professional development and training content. She has been the CEO and Founder of three companies in the field of applied skills, active learning both in an ILT, CBT and Web-Based environment. Dr. Pang also has over 20 years of entrepreneurial and operational experience in professional services, manufacturing and education oriented companies and has served as $\mathrm{CEO} / \mathrm{CFO} / \mathrm{CKO}$ and $\mathrm{COO}$ for several manufacturing, transportation and logistics elearning and professional services companies. Dr. Pang has been a speaker at numerous e-learning conferences, including the MEC 2001 Conference sponsored by Arizona State University, the 2001 Conference on Training and Knowledge Management sponsored by Generation 21 Learning Management Systems; E-Learn 2005 and Online Educa Berlin 2005, AACE/ED Media 2006, E-Learn 2006, E-Learning Guild 2006, CELDA 2007, and numerous other professional conferences.

\section{REFERENCES}

1. Ainley, M. D. (1993). Styles of engagement with learning: Multidimensional assessment of their relationship with strategy use and school achievement. Journal of Educational Psychology, 85, 395-405.

2. Basseches, M. (1984). Dialectical Thinking and Adult Development. Norwood, New Jersey: Ablex Publishing Corporation.

Bonwell, C., \& Elison, J. (1991). Active Learning: Creating Excitement in the Classroom. Washington: Clearing House on Higher Education.

3. Bransford, J., Brown, A., \& Cocking, R. (2000). How People Learn: Brain, Mind, and Experience \& School. Washington, DC: National Academy Press.

4. Bereiter, C. \& Scardamalia, M. (1989). Intentional Learning as a Goal of Instruction, In L. Resnick (Ed.), Knowing, Learning, and Instruction (pp. 361-392). Hillsdale, NJ:Lawrence Erlbaum Associates.

5. Bereiter, C., \& Scardamalia, M. (1993). Surpassing ourselves: An inquiry into the nature and implications of expertise. La Salle, IL: Open Court.

6. Brown, A. L. (1987). Executive control, self-regulation, and other more mysterious mechanisms. In F. Weinart \& R. Kluwe (Eds.), Metacognition, motivation and understanding (pp. 65-116). Hillsdale, NJ: Erlbaum.

7. Brown, A.L., \& Campione, J.C. (1994). Guided discovery in a community of learners. In K. McGilly (Ed.), Classroom lessons: Integrating cognitive theory and classroom practice (pp. 229-270). Cambridge, MA: MIT Press

8. Bruner, J. (1990). Acts of Meaning. Cambridge, MA: Harvard University Press.

9. Cannon-Bowers, J. A., Rhodenizer, L., Salas, E., \& Bowers, C. A (1998). A framework for understanding pre-practice conditions and their impact on learning. Personnel Psychology, 51(2), 291-320. 
10. Chan, C.K.K., \& Sachs, J. (2001). Beliefs about learning in children's understanding of science text. Contemporary Educational Psychology, 26(2), 192-210

11. Colajanni, B., Concialdi, S., \& Pellitteri, G.(2001). Construction or deconstruction: Which is the best way to learn architecture? Education \& Curricula, 12, 299-304.

12. Dean, D. W. (2006). How are scientific thinking skills best developed? Direct instruction vs. inquiry practice. Dissertation Abstracts International Section A: Humanities and Social Sciences, 67(4-A), pp. 1200.

13. Desoete, A., Roeyers, H., \& De Clercq, A. (2003). An off-line metacognition enhance mathematical problem solving? Journal of Educational Psychology, 95(1), 188-200.

14. Douglas, O, Burton, K. S., \& Reese-Durham, N. (2008). The effects of the multiple intelligence teaching strategy on the academic achievement of eighth grade math students. Journal of Instructional Psychology, 35(2), pp. 182-187.

15. Egan, D. E., and B. J. Schwartz. (1979). Chunking in the recall of symbolic drawings. Memory and Cognition, 7(2), 149-158

16. Ellis, R. (2001). The metaphorical constructions of second language learners. In Breen, M.P. (ed.). Learner Contributions to Language Learning (pp. 65-85). London: Pearson Education.

17. Fink ,L. D.( 2003). Creating Significant Learning Experiences. San Francisco: Jossey-Bass.

18. Flavell, J. H. (1979). Metacognition and cognitive monitoring: A new area of cognitive developmental inquiry. American Psychologist, 34, 906-911.

19. Ford, J. K., \& Kraiger, K. (1995). The application of cognitive constructs and principles to the instructional systems design model of training: Implications for needs assessment, design, and transfer. International Review of Industrial and Organizational Psychology, 10, 1-48.

20. Garner, R., \& Alexander, P. A. (1989). Metacognition: Answered and unanswered questions. Educational Psychologist, 24, 143-148.

21. Georghiades, P. (2004). From the general to the situated: three decades of metacognition. International Journal of Science Education, 26(3), 365-385

22. Giesbrecht, N. (1996). Strategies for developing and delivering introductory-level statistics and methodology courses (Report No. SE057914). Alberta, Canada: University of Calgary. (ERIC Document Reproduction Service No. ED393668).

23. Graffam, B. (2007). Active learning in medical education: Strategies for beginning implementation. Medical Teacher, 29, 38-42.

24. Hartman, H. J. (2001). Developing students' metacognitive knowledge and skills. In H. Hartman (Ed.), Metacognition in learning and instruction (pp. 33-68). Dordrecht: Kluwer.

25. Hativa N. (2000). Becoming a better teacher: a case of changing the pedagogical knowledge and beliefs of law professors. Instructional Science 28, 491-523.

26. Hofer, B. (2004). Epistemological understanding as a metacognitive process: Thinking aloud during online searching. Educational Psychologist, 39(1), 43-55.

27. Hofer, B. K., \& Pintrich, P. R. (1997). The development of epistemological theories: beliefs about knowledge and knowing and their relation to learning. Review of Educational Research, 67, 88-140.

28. Hofer, B. K., Yu, S. L., \& Pintrich, P. R. (1998). Teaching college students to be self-regulated learners. In D. H. Schunk \& B. J. Zimmerman (Eds.), Self-regulated learning: From teaching to self-reflective practice (pp. 57-85). New York: Guilford.

29. Huitt, W. (2003). Constructivism. Educational Psychology Interactive. Retrieved June 16, 2008, from http://chiron.valdosta.edu/whuitt/col/cogsys/construct.html

30. Ivancic, K. \& Hesketh, B. (2000). Learning from errors in a driving simulation: Effects on driving skill and self-confidence, Ergonomics, 43, 1966-84.

31. Kegan, R. (1994). In over our heads: The mental demands of modern life. Cambridge, MA: Harvard University Press.

32. Keith, N., \& Frese, M. (2005). Self-regulation in error-management training: Emotion control and metacognition as mediators of performance effects. Journal of Applied Psychology, 90, 677-691.

33. King, P. M., \& Kitchener, K. S. (1994). Developing reflective judgment: Understanding and promoting intellectual growth and critical thinking in adolescents and adults. San Francisco: Jossey-Bass.

34. Kintsch, W. (1998). Comprehension: A paradigm for cognition. Cambridge, United Kingdom: Cambridge University Press. 
35. Kuhn, D. (1991). The skills of argument. Cambridge, England: Cambridge University Press.

36. Law, Y. K., Chan, C. K. K., \& Sachs, J. (2008). Beliefs about learning, self-regulated strategies and text comprehension among Chinese children. British Journal of Educational Psychology, 78, 51-73.

37. Mason, L. (2003). Personal epistemologies and intentional conceptual change. In G. M. Sinatra \& P. R. Pintrich (Eds.), Intentional Conceptual Change (pp. 199-236). Mahwah, NJ: Lawrence Erlbaum Associates.

38. McKeachie, W. J. (1974) The decline and fall of the laws of learning. Educational Researcher, 3, 7-11.

39. Minnaert, A., \& Janssen, P. J. (1992). Success and progress in higher education: A structural model of studying. British Journal of Educational Psychology, 62(2), 184-192.

40. Newell, J., Dahm, K, Harvey, R, \& Newell, H. (2004). Developing metacognitive engineering teams. Chemical Engineering Education, 316-320.

41. Novick, L. R. \& Holyoak, K. J. (1991). Mathematical problem solving by analogy. Journal of Experimental Psychology: Learning, Memory, and Cognition, 17(3), 398-415.

42. Ormrod, J.E. (1999). Human Learning (3rd Ed.). Upper Saddle River, NJ: Prentice-Hall.

43. Pang, K. (2008). The metacognitive expertise assessment tool: A predictive scale for academic achievement across disciplines. Dissertation Abstracts International (UMI No. AAT 3304568).

44. Pintrich, P. R. (2000). An achievement goal theory perspective on issues in motivation terminology, theory, and research. Contemporary Educational Psychology, 25, 92-104.

45. Pintrich, P.R., McKeachie, W.J., \& Lin, Y. (1987). Teaching a course in learning to learn. Teaching of Psychology, 14, 81-86.

46. Reeves, J. A. \& S. A. Francis (2002). A comparison between two methods of teaching pharmacists about adverse drug reaction: problem based learning versus a didactic lecture. Pharmacy education, 1(1), 25-35.

47. Salas, E., \& Cannon-Bowers, A. (2001). The science of training: A decade of progress. Annual Review of Psychology, 52, 471-499.

48. Samaha, J. (2008). Criminal Law. CA: Thomson Learning.

49. Schoenfeld, A. H. (1987). Cognitive science and mathematics education. Hillsdale, NJ: Erlbaum.

50. Schommer, M. A. (1993). Comparisons of beliefs about the nature of knowledge and learning among postsecondary students. Research in Higher Education, 34(3), 355-370.

51. Schraw, G. \& Sinatra, G. (2004). Epistemological development and its impact on cognition in academic domains. Contemporary Educational Psychology, 29(2), 95-102.

52. Stearns, H., Gargus, J., Schuetze, M., \& Lombardi, J. (2006). Simplified Distributed Authoring Via Component-based Object Construction and Deconstruction in Collaborative Croquet Spaces. Retrieved October 31, 2008 from http://www.opencroquet.org/images/c/c4/2006_BrieUserExperience.pdf

53. Stewart, P. W., Cooper, S. S., \& Moulding, L. R. (2007). Metacognitive development in professional educators. The Researcher, 21(1), 32-40.

54. Sweller, J., Mawer, R. F., \& Ward, M. R. (1983). Development of expertise in mathematical problem solving. Journal of Experimental Psychology, 11, 639-661.

55. Tsai, C. C. (2004a). Beyond cognitive and metacognitive tools: The use of the Internet as an "epistemological" tool for instruction. British Journal of Educational Technology, 35, 525-536.

56. Tu, Y.W., Shih, M., \& Tsai, C. C. (2008). Eighth graders' web searching strategies and outcomes: The role of task types, web experiences and epistemological beliefs. Computers \& Education 51, 1142-1153.

57. Vaughn, L., Gonzalez Del Rey, J., \& Baker R. (2001). Microburst teaching and learning. Med Teach, 23(1), 39-43.

58. Wells, G. (1985). Language, Learning and Education. Law Book Co of Australasia.

59. Winne, P. H., \& Hadwin, A. F. (1998). Studying as self-regulated learning. In D. J. Hacker, J. Dunlosky \& A. C. Graesser (Eds.), Metacognition in educational theory and practice (pp. 277--304). Mahwah, NJ: Lawrence Erlbaum Associates. 